\title{
A LUA NA MÃO: MEDIAC̣ÃO E CONCEITOS COMPLEXOS NO ENSINO DE ASTRONOMIA
}

\author{
LEONARDO LAGO ${ }^{*}$ \\ https://orcid.org/0000-0002-3143-1757 \\ JOSÉ LUIS ORTEGA ${ }^{2 *}$ \\ https://orcid.org/0000-0002-1791-543X \\ CRISTIANO MATTOS ${ }^{3 * *}$ \\ https://orcid.org/0000-0001-5927-8742
}

RESUMO: Neste trabalho apresentamos uma atividade escolar de observação e registro das fases da Lua, e discutimos os resultados à luz da teoria vygotskiana de mediação e formação de conceitos. Mostramos como alterações na atividade permitiram aos estudantes elaborar modelos cada vez mais complexos de fases da Lua, ao apropriarem instrumentos mediadores com maiores graus de generalidade. Isto possibilitou aos estudantes estabelecer relações com o fenômeno contextualmente mais ricas e cientificamente mais precisas. Os dados empíricos são produções dos estudantes durante os três anos nos quais a atividade foi modificada. Discutimos os resultados em termos do desenvolvimento da atividade e da consciência dos estudantes sobre o fenômeno na medida que explicavam, previam e construíam o modelo científico de forma cada vez mais complexa. Palavras-chave: Formação de conceitos; Mediação; Ensino de Astronomia.

\section{LA LUNA EN LA MANO: MEDIACIÓN Y CONCEPTOS COMPLEJOS EM LA ENSEÑANZA DE LA ASTRONOMIA}

RESUMEN: En este trabajo, presentamos una actividad escolar relativa a la observación y registro de las fases de la Luna y discutimos los resultados a la luz de la teoría vygotskiana de mediación y formación de conceptos. Mostramos cómo cambios en la actividad permitieron a los estudiantes elaborar modelos cada vez más complejos de las fases de la Luna, al apropiarse de instrumentos mediadores con más grados de generalidad. Esto les permitió establecer relaciones con el fenómeno, contextualmente más ricas y científicamente más precisas. Los datos utilizados

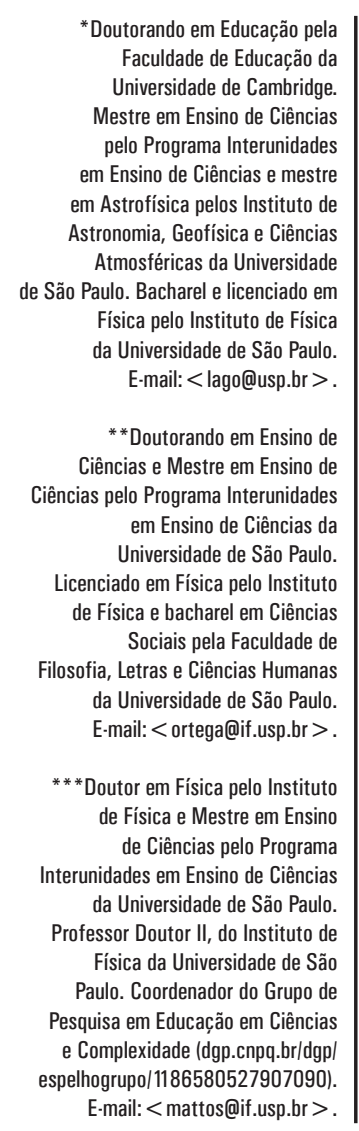

\footnotetext{
${ }^{1}$ Universidade de Cambridge, Faculdade de Educação, Cambrige - Reino Unido.

2 Universidade de São Paulo, Programa Interunidades em Ensino de Ciências, São Paulo, SP - Brasil.

${ }^{3}$ Universidade de São Paulo, Instituto de Física, São Paulo, SP - Brasil.
} 
son producciones de los estudiantes durante los tres años en que la actividad fue modificada. Discutimos los resultados en términos del desarrollo de la actividad y de la conciencia de los estudiantes sobre el fenómeno, mostrando cómo ellos lograron explicar, predecir y construir el modelo científico de forma cada vez más compleja.

Palabras clave: Formación de conceptos; Mediación; Enseñanza de la Astronomía

THE MOON IN MY HAND: MEDIATION AND COMPLEX CONCEPTS IN ASTRONOMY TEACHING

ABSTRACT: In this work, we present a school science's activity regarding observation and recording of the moon phases and discuss the results in light of the Vygotskian theory of mediation and concepts formation. We show how changes in the activity allowed students to elaborate increasingly complex models of moon phases, by appropriating mediating instruments with higher degrees of generality. This enabled students to establish contextually richer and more scientifically precise relationships with the phenomenon. The data comprises student productions during the three years in which the activity was modified. We discuss the results in terms of the development of activity and students' conscious awareness about the phenomenon when they explained, predicted and built the scientific model in gradually more complex ways.

Keywords: Concepts formation; Mediation; Astronomy teaching. 


\section{INTRODUÇÃO}

A Astronomia vem sendo apontada como uma ciência imprescindível na vida dos estudantes da educação básica (PASACHOFF; PERCY, 2005; SOLER; LEITE, 2012), por ser capaz de nutrir reflexões sobre a presença e o futuro dos seres humanos no Universo, não só por dimensionar o problema da localização espacial no cosmos, mas também por levantar questionamentos sobre as possibilidades de permanência num universo dinâmico e em expansão (NAS, 2001). A compreensão das relações que o homem construiu com o universo em que vive, ao longo de sua história, está permeada pela criação de mediações que permitiram tornar mais complexa a visão do nosso lugar no espaço e no tempo (JAFELICE, 2010; SODRÉ, 2017).

Uma variedade de abordagens e pontos de vista estão suportados por uma diversidade de práticas sociais construídas ao longo da história humana (LAGO, 2013) que, no início, davam conta, principalmente, de modos de localização ou de orientação no tempo e no espaço (SODRÉ, 2017) e, depois, produziram práticas de exploração e modelagem cósmica. Nesse processo, contraditoriamente, a complexificação alcançada em teorias e modelos científicos afastou do leigo, a possibilidade de compreender, não só sua localização no espaço, mas também as relações de significado entre sua vida cotidiana e o movimento dos astros no céu (ENGESTRÖM, 1991).

Contudo, no processo educacional, as disciplinas científicas na educação básica, principalmente na passagem do ensino fundamental para o ensino médio, demandam de maneira mais aprofundada que os estudantes mobilizem e relacionem uma série de conhecimentos, como podemos identificar nas novas demandas curriculares nos mais diversos países do mundo (e.g. BRASIL, 2017; NGSS, 2013), que resgatam essa complexidade como ferramenta de compreensão e intervenção no mundo. Nessa perspectiva, tais conhecimentos deixariam de ser apenas objetos a serem descobertos, mas ferramentas investigativas para lidar com objetos mais complexos do conhecimento científico e com uma linguagem mais elaborada (MATTOS, 2014). Quando nos apropriamos de modelos científicos como ferramenta, conseguimos lidar com uma quantidade de relações organizadoras da atividade que, além de ressignificar as relações iniciais do aprendiz com o mundo, seu conhecimento prévio, amplia suas formas de resolver novas situações, recontextualizando suas formas de ser no mundo (CAMILLO; MATTTOS, 2010).

Tomando como exemplo o tema científico que nos interessa neste trabalho, as fases da Lua, Lelliott e Rollnick (2010) revisaram a literatura sobre o ensino da Astronomia e apontaram o quão desafiador é, para a maioria das pessoas, compreender o fenômeno: "apesar dos estudantes serem capazes de descrever as fases da Lua, a maioria deles são incapazes de explicar por que as fases ocorrem, ou dar uma explicação coerente do sistema Terra-Sol-Lua.” (p.1786, grifo dos autores, tradução nossa). ${ }^{1}$ Nessa mesma revisão, diversos trabalhos indicam que as concepções de estudantes e professores sobre a formação das fases lunares também são problemáticas, pois muitos insistem em atribuir a parte escura de uma fase lunar a 'alguma coisa no caminho', obstruindo a luz, sendo a Terra, o obstáculo mais comumente considerado como causa dessa obstrução. Já há algum tempo, Baxter (1989) categorizou, em cinco grupos, as concepções elaboradas por crianças e adolescentes, a respeito das causas das fases da Lua: i) Nuvens cobrem 
a parte da Lua; ii) Planetas fazem sombra sobre a Lua; iii) A sombra do Sol é projetada sobre a Lua; iv) A sombra da Terra é projetada sobre a Lua e v) Porção iluminada da Lua e visível da Terra. Esses resultados são amplamente confirmados por outros estudos, nos quais, grosso modo, entre 30\% e 50\% dos sujeitos explicam as fases da Lua pela projeção da sombra da Terra, enquanto que somente um número entre 5\% e 20\% admitem o modelo científico (CAMINO, 1995; IACHEL; LANGHI; SCALVI, 2008; KALKAN; KIROGLU, 2007; KAVANAGH; AGAN; SNEIDER, 2005; KIKAS, 1998; MULHOLLAND; GINNS, 2008; PLUMMER; ZAHM, 2010; TREVISAN; PUZZO, 2006; TRUNDLE et al., 2010).

Assim, tendo como objetivo a superação dessa lacuna no aprendizado e na compreensão sobre o fenômeno lunar, descrevemos neste trabalho um estudo longitudinal sobre a condução de uma atividade de observação e registro das fases da Lua em turmas do último ano do ensino fundamental. $\mathrm{Na}$ análise desse material, procuramos entender como observações e registros livres tornaram-se mais ricos e complexos, na medida em que diferentes ferramentas conceituais e digitais foram introduzidas na atividade. Nossa hipótese é que as novas ferramentas permitiram a criação de outras mediações entre os estudantes e seu objeto de estudo, facilitando a aprendizagem e a elaboração conceitual do fenômeno da lunação. Em outros termos, a participação em atividades que estimulam a capacidade de realizar registros e previsões de maneira mais dinâmica e a apropriação dos instrumentos conceituais e investigativos nessas atividades, ampliaram o repertório simbólico dos envolvidos e estabeleceram novas relações entre estudante, objeto científico e prática científica. Em suma, tornaram mais complexos os conceitos e a consciência dos estudantes.

Nessa investigação, partimos dos trabalhos de Vygotsky para compreender o processo de complexificação de um conceito científico. A perspectiva históricocultural, aqui se justifica pelo desenvolvimento de um conjunto de atividades cuja finalidade é a de promover a ampliação da consciência dos sujeitos no que diz respeito às fases da Lua.

\section{REFERENCIAL TEÓRICO: MEDIAC̣ÃO E COMPLEXIFICAC̣̃̃O DE CONCEITOS}

A expressão que utilizamos no título do artigo, 'Lua na mão', foi escolhida por nos remeter a um duplo processo: o de operação com instrumentos culturais mediadores e o de apropriação dos sentidos mobilizados pela atividade humana, na qual se dispõem e se organizam esses instrumentos. Em síntese, aqui procuramos mostrar como instrumentos mediadores se tornam mais complexos ao longo da evolução de uma atividade escolar. A complexificação se dá na mobilização, aprendizado e desenvolvimento de novos conceitos e relações dos estudantes com o objeto, ou seja, apresentam novas formas de enunciar o fenômeno, ressignificando, assim, o que está sendo estudado (ORTEGA, 2012).

\subsection{MEDIAÇ̃̃O}

Uma das principais bases do programa de pesquisa de Vygotsky foi compreender a gênese das funções mentais superiores, isto é, compreender como se desenvolvem os processos mentais tipicamente humanos como "atenção 
voluntária, memória lógica, formação de conceitos e volição.” (VYGOTSKY, 1997, p.106, tradução nossa). ${ }^{2}$ Para tratar do problema da gênese de tais funções, Vygotsky aponta que essas não são inatas aos seres humanos, mas têm sua origem e desenvolvimento na interação com outros seres humanos, em um processo nomeado de interiorização ou internalização (KOZULIN, 1998; VERESOV, 2010). Vygotsky enuncia duas leis fundamentais que dariam suporte a esse processo de interiorização: a lei genética do desenvolvimento cultural e a lei da sociogênese das formas superiores de comportamento (VYGOTSKY, 1998). Enquanto a primeira lei explicita o plano social na gênese dos processos psicológicos, a segunda enfatiza especificamente o papel fundamental da linguagem - mais especificamente da fala - ao destacar sua unidade e interdependência com o pensamento.

Para descrever os mecanismos subjacentes àquelas leis, Vygotsky discrimina relações imediatas e mediadas entre um estímulo e a respectiva resposta dada por um sujeito. Ao relacionar essas diferentes formas de desenvolvimento com os processos mentais, Vygotsky esclarece a natureza diferenciada das operações mentais inferiores e superiores. Enquanto as primeiras são imediatas, as últimas são mediadas, ou seja, caracterizadas pela mediação. O ponto central nessa argumentação é que entre um estímulo e a resposta complexa dada por um sujeito está o processo intelectivo das funções mentais superiores. Assim, ao afirmar que a relação é mediada, Vygotsky conclui que as próprias funções mentais superiores são mediadas (MILLER, 2011; VERESOV, 2010).

Em outras palavras, desenvolveu-se a ideia da mediação por signos instrumentos culturais - que estão intrinsecamente ligados a objetos de diferente natureza como palavras, conceitos, números, diagramas, mapas entre outros. Nessa perspectiva, ao operar com signos, um sujeito passa a apropriar as funções sígnicas como formas culturais de comportamento e ação. Ao longo do processo ontogenético de formação do sujeito, a operação com signos é cada vez menos interpsicológica, para se tornar um sistema psicológico complexo: "O que era uma operação externa com signo, um certo método cultural de controle externo, é convertido em uma nova camada intrapsicológica e dá origem a um novo sistema psicológico" (VYGOTSKY, 1999 , p.55, tradução nossa). ${ }^{3}$ Esse novo sistema é então considerado qualitativamente superior em relação anterior e de gênese cultural-psicológica.

Comentadores e intérpretes endossam essa interpretação sobre a incorporação da operação com signos. Por exemplo, enquanto Veresov (2010) expressa a ideia em termos de uma reorganização qualitativa das funções psicológicas, Davydov e Zinchenko (1993) reforçam que a incorporação de signos na estrutura das funções mentais é a base para a formação da consciência. Em outras palavras, como os signos são produtos socioculturais, o controle dessas funções superiores é gestado, portanto, no curso do desenvolvimento dos indivíduos. Destaca-se, contudo, que esse processo de apropriação dos signos e controle do comportamento não ocorre no sentido de subjugar o ser humano, mas, ao contrário, como um caminho para este expressar e desenvolver sua volição (DANIELS, 2015).

Ou seja, a proposição vygotskiana é a de que signos culturais são apropriados como ferramentas psicológicas (DANIELS, 2001; KOZULIN, 2003; MERCER, 2000; WERTSCH, 1991). A ideia de ferramenta vem da analogia com 
o instrumento material que serve como mediador entre sujeito e o objeto de sua ação na natureza. No caso das ferramentas psicológicas, Vygotsky destaca o papel central da linguagem e dos conceitos como ferramentas para o pensamento (VYGOTSKY, 1997). Na literatura, encontra-se o termo mediação semiótica para designar a mediação que é feita exclusivamente pela linguagem (HASAN, 2012; WELLS, 2012). Apesar de termos uma posição mais dialética no que se refere às relações entre linguagem e atividade humana, entendemos que esse destaque ajuda a ressaltar o papel das interações discursivas entre os sujeitos para o desenvolvimento das ferramentas psicológicas. Por exemplo, tomando-se um mapa como uma forma representativa de instrumento cultural, podemos dizer que seu uso, como solução de determinada tarefa de localização geográfica, não é feito no vazio social, mas imerso nas negociações de sentidos das finalidades desse uso: mobilidade urbana, estratégia militar, apreciação turística entre outros, pois é por meio delas que os sujeitos se engajam na atividade com os outros.

Em outro exemplo, Vygotsky argumenta que da mesma forma que o estudo e domínio de língua estrangeira eleva o domínio da língua materna, o domínio da linguagem algébrica elevaria o pensamento matemático a um nível superior, libertando, assim, "o pensamento da criança da prisão das dependências numéricas concretas” (VYGOTSKY, 2009, p. 267). Esses pontos serão explorados na análise dos dados de nossa intervenção.

\subsection{FORMAC̣ÃO DE CONCEITOS}

Abordaremos, agora, o estudo da formação de conceitos tal como aparece no programa vygotskiano. Nosso objetivo é relacionar a operação por signos e sua apropriação como ferramenta psicológica como elementos centrais da formação de conceitos, que desenvolveremos, posteriormente, como complexificação conceitual.

Para Vygotsky (2009), a aprendizagem de um conceito é um complexo processo psicológico elaborado por toda a vida de um sujeito, "no momento em que uma criança toma o conhecimento pela primeira vez do significado de uma nova palavra, o processo de desenvolvimento dos conceitos não termina, mas está apenas começando." (VYGOTSKY, 2009, p. 250). Nesse percurso, ocorrem operações mentais que culminam em determinado significado de uma palavra que carrega o conceito. Ele caracteriza o pensamento conceitual numa interdependência com a linguagem, chegando a tomar os termos conceitos e significado da palavra como sinônimos.

Entendemos aqui, que em cada nova atividade, quando sujeitos operam com signos, novas mediações emergem e, consequentemente, novos sentidos do conceito se instauram. Assim, o papel da mediação por signos e de sua apropriação como ferramentas psicológicas são imprescindíveis para a formação dos conceitos, não como elementos isolados, mas construídos dentro de um sistema de conceitos, cada vez mais complexo. Em nossos termos, novas mediações expressam-se na complexificação conceitual. De fato, Vygotsky (2009) explica que a existência de um sistema de conceitos não é nada mais do que "a existência de relações entre os conceitos" (p. 294) e que "todo conceito pode ser designado por uma infinidade de meios por intermédio de outros conceitos” (p. 364). O que Vygotsky esboça e descreve nessas passagens é a formação contínua de um sistema conceitual, a complexificação conceitual. 


\begin{abstract}
Mas se depois desse conceito surge um conceito superior, ele pressupõe necessariamente a existência não de um, mas de uma série de conceitos co-subordinados, com os quais esse conceito está em relações determinadas pelo sistema de conceito superior, sem o que, esse conceito superior não seria superior em relação a outro. Esse mesmo conceito superior pressupõe, simultaneamente, uma sistematização hierárquica até dos conceitos inferiores àquele conceito e a ele subordinados com os quais ele torna a vincular-se através de um sistema de relações inteiramente determinado. (VYGOTSKY, 2009, p. 292)
\end{abstract}

Assim, os conceitos são estruturas mediadoras e formadoras do pensamento, das quais nos apropriamos em atividade, interagindo com diferentes signos mediadores. A contínua interação do sujeito com os mais variados signos, leva-o a apropriá-los como instrumentos mediadores, que revelam a dinâmica da complexificação conceitual. Produzimos, então, um sistema de conceitos, caracterizado por uma dinâmica entre sistemas de sistemas conceituais, um complexo de complexos conceituais. O conceito é "uma profunda e penetrante reflexão de um objeto da realidade em toda sua complexidade e diversidade, em conexões e relações com todo o resto da realidade." (VYGOTSKY, 1998, p. 54, tradução nossa). ${ }^{4}$ Sendo radicalmente dialético, o conceito expressa uma complexa trama de relações que sustentam uma realidade fundada por uma práxis social e historicamente determinada.

Na próxima seção, a partir desse argumento, descreveremos a aprendizagem de conceitos e discutiremos, empiricamente, a proposta de ensino e aprendizagem como o contínuo processo de interação com signos e de sua apropriação como ferramentas psicológicas. A gênese dessas ferramentas é instauradora da dinâmica de atribuição de sentidos a um objeto, fenômeno ou situação. A essa dinâmica atribuímos o processo de complexificação dos conceitos, não só na diferença de conteúdo, mas também nas relações estabelecidas no sistema de conceitos, consequentemente nas relações que o sujeito estabelece com o mundo. Ou seja, a formação de conceitos tomada na perspectiva de uma lógica formal binária reduz o produto educacional a: aprendeu ou não aprendeu. Entretanto, numa perspectiva dialética, o aprendizado de conceitos como um processo de complexificação de conceitos, implica na ampliação de relações e usos contextuais, ou seja, novos e mais complexos campos mediadores para tomada de consciência de novos sentidos e significados que expressam o próprio processo de aprendizagem (MATTOS, 2014, 2016).

\title{
2. METODOLOGIA
}

Neste trabalho, analisamos o efeito da introdução de diferentes instrumentos mediadores em uma atividade didática de introdução à Astronomia, na qual são trabalhadas a observação e o registro das fases da Lua. Os dados constituem-se de registros dos estudantes do nono ano do ensino fundamental ao longo de três anos de aplicação da atividade. Este trabalho tem origem na investigação realizada por Lago (2013), a qual se constituía da realização de uma sequência de ensino e aprendizagem com doze aulas sobre o satélite terrestre. Em continuidade a este trabalho, a atividade didática continuou a ser realizada nos dois anos subsequentes à primeira aplicação na mesma escola. Ao longo dos anos foram introduzidas alterações buscando o aprimoramento da relação de ensino e 
aprendizagem e superação de problemas encontrados na primeira versão, que foi tomada praticamente como um piloto da atividade. Nesta seção, descreveremos com detalhes o piloto e seu desenvolvimento subsequente.

Planejamos a observação e registro das fases da Lua como a primeira de uma sequência de doze atividades didáticas. A sequência de ensino, na sua totalidade, tinha dois objetivos principais de aprendizagem: i) aprender o nosso satélite como um objeto astronômico passível de investigação e modelização científica, e ii) expandir o objeto Lua para além da disciplina científica, englobando, por exemplo, as disciplinas de História, Arte e Literatura, além da cultura popular. A descrição completa das atividades está discutida em Lago (2013), e aqui entendemos ser necessário apenas apontar que as outras atividades versavam sobre: as unidades de medidas utilizadas na Astronomia e a escala do sistema Terra-Sol-Lua; modelagem do fenômeno das fases da Lua e eclipses com maquetes; sistematização desses fenômenos com uso de recursos digitais; utilização de episódios da história da ciência; discussão sobre as teorias de formação da Lua e filosofia da ciência; além do estudo sobre outras luas do Sistema Solar. Associado ao conteúdo conceitual, mobilizaram-se diversas competências e habilidades, como: articulação e relação de múltiplos registros; raciocínio matemático de proporcionalidade e de espacialidade; visualização dinâmica do céu e da Lua; exploração de marcos e referências, método científico e escrita argumentativa.

A sequência de atividades foi organizada num diálogo entre os resultados vindos de um levantamento da literatura de Ensino de Astronomia e a experiência prévia do professor que faria a intervenção, no ensino de tópicos desse conteúdo para o nível fundamental. Desde o início, pesquisadores e professor trabalharam de maneira colaborativa, estabelecendo um diálogo produtivo dentro de um espaço de trocas, construções e reflexões coletivas. O professor é reconhecido na escola por sua postura dialógica em sala de aula, tendo larga experiência na produção de seu próprio material didático, extremamente contextualizado nas situações vivenciais dos estudantes. Em suas aulas, cria momentos para a manifestação dos estudantes, convidando-os a explicitar suas concepções. Por outro lado, o professor tem, também, experiência na pesquisa acadêmica, participando desse trabalho como coautor.

Sobre a escola, trata-se de uma instituição secular privada localizada na zona sul da cidade de São Paulo que atende, primordialmente, a classe média da região. Nos últimos anos, a escola possui de três e quatro turmas para cada nível do ensino fundamental com cerca de 25 estudantes cada. A coordenação da escola apoiou o professor, dando liberdade tanto para as suas atividades de ensino como de pesquisa, com o objetivo de revitalizar o Ensino de Ciências Naturais no último ano do ensino fundamental. Como consequência a Astronomia se tornou o eixo estruturador desse nível de ensino na escola.

Após o primeiro ano, o professor, consciente das dificuldades de execução surgidas na prática e das transformações necessárias do que fora planejado, passa a incluir, nos anos seguinte, novas ferramentas e mediações nas atividades, o que permitiu que os estudantes desenvolvessem novas compreensões sobre os conceitos astronômicos envolvidos. Dentre as modificações implementadas pelo professor destacamos a inclusão de aplicativos de reconhecimento do céu em um dispositivo móvel - celular ou tablet - e o uso de marcadores físicos - papéis do tipo post it - para um registro permanente e estático da posição da Lua no céu. Essas 
alterações permitiram que estudantes e professor transformassem seus quartos de dormir e a sala de aula em um observatório permanente. Aqui analisamos como as observações e registros livres são enriquecidos e complexificados quando novos instrumentos mediadores são incluídos na atividade. Consideramos este trabalho como um estudo longitudinal de três anos, no qual se estabeleceram dois ciclos de reflexão que permitiram o planejamento de melhores situações de aprendizagem.

\subsection{CONTEXTO DA ATIVIDADE DE OBSERVAC̣ÃO DA LUA}

A atividade intitulada 'Observação da Lua' tinha como objetivo propor que os estudantes elaborassem uma série de registros observacionais diários da Lua sempre no mesmo horário. ${ }^{5}$ Os registros, que deveriam ocorrer ao longo de duas semanas, deveriam ser constituídos por desenhos das fases e posição relativa da Lua no céu mas, posteriormente, permitiu-se a possibilidade de utilizar fotografias tiradas pelos próprios alunos. A atividade teve seu início planejado para um dia de Lua Nova, pois o fato de não haver Lua no céu durante todo o período noturno poderia instigar alguns estudantes desde o início a refletirem sobre o fenômeno. No caso, referimo-nos à crença de que a Lua está sempre presente no céu noturno e que pode influenciar na construção do modelo. Outro motivo para escolha do início pela fase da Lua Nova foi a de dar oportunidade aos estudantes de analisar por completo meio ciclo lunar, da Lua Nova até a fase de Lua Cheia. Optou-se, também, por fixar o horário de observação diária do astro sempre às $18 \mathrm{~h}$. Nesse horário, é possível determinar com precisão a posição do Sol - sempre se pondo no horizonte oeste - permitindo ao estudante relacionar mais facilmente a posição da Lua relativa ao Sol com sua aparência. As instruções para atividade, tal como recebidas pelos estudantes, são mostradas na Figura 1.

\section{1) Observação da Lua (início: $10 / 02$ - domingo)}

Nos próximos quinze dias observem e registrem, sempre no mesmo desenho, a forma e a posição da Lua no céu. Faça os registros sempre no mesmo local e sempre no mesmo horário, às $18 \mathrm{~h} 00$, logo depois do pôr do Sol.

Para isto façam um desenho do horizonte, utilizando casas, prédios e árvores como pontos de referência e a cada dia, façam uma representação de onde e como a Lua parece no céu. O desenho abaixo é somente um modelo.

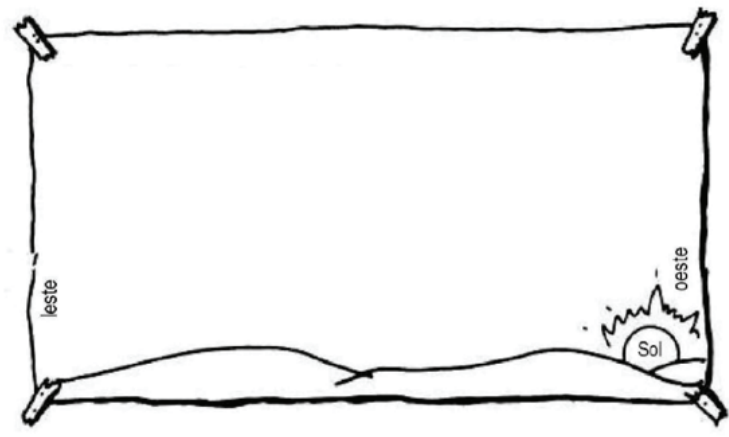

Figura 1. As instruções da atividade de observação da Lua (Adaptado de Kavanagh et al. 2005). 
As instruções incluíam ainda um cenário com horizonte aberto, no qual mostrava o Sol poente, para que os estudantes reunissem parte dos registros em um único diagrama. A expectativa era de que o modelo do diagrama ajudasse os estudantes na exploração de marcos de referências e dos pontos cardeais, além de permitir que eles associassem uma terceira variável às observações: a altura da Lua em relação ao horizonte.

Assim, na hipótese dos estudantes apontarem corretamente as alturas da Lua em relação ao horizonte - juntamente com sua aparência e posição relativa ao Sol - teriam produzido um modelo que poderia, em tese, permitir a visualização do movimento de lunação. O diagrama seria a sistematização das observações do movimento, ou seja, estariam registradas as posições da Lua no momento do experimento, conferindo assim maior confiança ao dado observado em uma atividade seguinte sobre a modelização das fases lunares. Por outro lado, o diagrama serve, também, como um modelo científico construído pelos próprios estudantes e que poderia ser utilizado para identificar tendências na trajetória da Lua em torno da Terra, ou seja, identificar a sequência das fases em relação ao Sol e ao cenário, como o exemplo do possível diagrama representado na Figura 2.

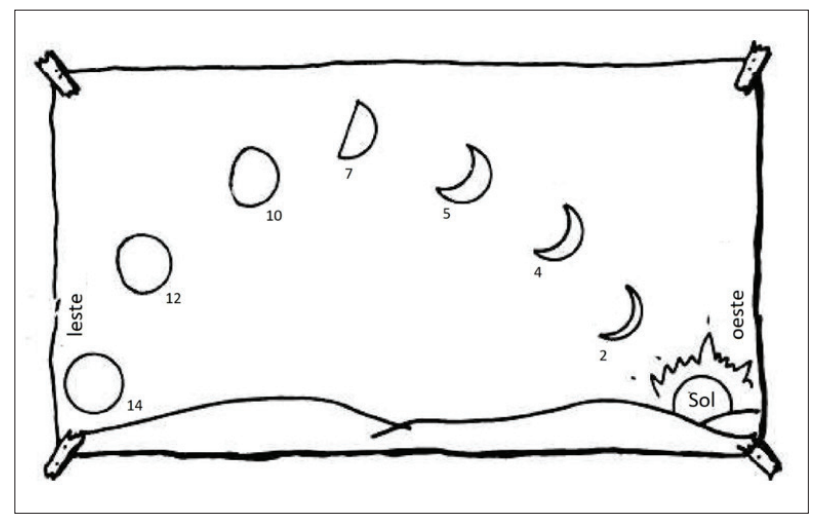

Figura 2. Exemplo de diagrama esperado com as informações que se esperava que os estudantes incluíssem na figura (Adaptado de Kavanagh et al. 2005).

Sabe-se que a cada dia, por causa de seu movimento de revolução, a Lua nasce aproximadamente 50 minutos mais tarde considerando-se o dia anterior. Para um observador na Terra, a Lua Nova nasce com ângulo muito próximo ao Sol (antes da posição 2 na Figura 2), por volta das 6 h e, naturalmente, se põe com ele, em torno das 18h. A partir desse dia, a Lua nasce cada vez mais tarde, portanto visível antes do entardecer, cada vez mais cheia e mais perto do lado leste do horizonte. Ou seja, o registro feito pelos estudantes, sempre às $18 \mathrm{~h}$, deveria indicar o astro cada vez mais iluminado e deslocado para leste. Ao longo das duas semanas, nesse horário, o registro deveria indicar que a Lua percorreu o céu, indo do horizonte oeste, passando pelo alto do céu, até o horizonte leste e, no último dia, no momento da observação, a Lua nasceria totalmente cheia no horizonte leste (posição 14 na Figura 2).

Nossa expectativa era a de que a operação com o diagrama permitisse aos estudantes estabelecer outra relação com o objeto lunar, não apenas como 'algo' 
no céu, mas como um objeto a ser investigado e modelado, o qual apropriariam cientificamente, a ponto de elaborarem explicações sobre seus mecanismos e de realizarem previsões sobre suas futuras posições e fases. Contudo, como veremos a seguir, os resultados da primeira aplicação da atividade não foram os esperados, o que levou o professor a propor alterações na atividade, nos anos seguintes.

Destacamos que a construção de representações a partir da posição de um observador terrestre é pouco comum nos livros didáticos brasileiros, já que seus autores, de maneira geral, preferem ilustrar o modelo das fases da Lua a partir da perspectiva em que o observador se encontra fora do plano da órbita terrestre (LAGO, 2013).

\section{APRESENTAC̣ÃO E DISCUSSÃO DOS DADOS}

Como apontamos nos objetivos deste trabalho, explicitaremos as transformações da atividade com a inclusão de novos instrumentos mediadores e o consequente processo de complexificação dos conceitos no aprendizado dos estudantes. Novos conceitos e relações são estabelecidos pelos estudantes ao longo da transformação da atividade que se manifestam como novas formas de enunciar o fenômeno estudado.

Os dados estão apresentados e discutidos em três partes relativas a cada uma das versões realizadas ao longo dos três anos nos quais a atividade foi desenvolvida. O que chamamos de primeiro ano, consta dos registros oriundos da atividade piloto, tal como descrita anteriormente, na qual o principal meio de registro foi o desenho no papel. No segundo ano, o registro foi realizado por meio de dispositivos móveis, o que também apresentou limitações na representação do fenômeno, o que nos levou, na versão do terceiro ano de aplicação da atividade, à proposição de integração das duas ferramentas mediadoras em uma mais complexa, a qual chamamos de 'papel expandido'. Assim, em forma de narrativa, vamos caracterizar e analisar esses três momentos pelo tipo de registro dominante estabelecido pelos estudantes, frente ao referencial teórico adotado.

\subsection{PRIMEIRO ANO DE APLICAÇ̃̃O DA ATIVIDADE: O REGISTRO DA OBSERVAC̣ÃO DA LUA POR DESENHOS EM PAPEL OU POR FOTOGRAFIAS}

Nessa atividade, o aluno deveria observar a Lua a olho nu e registrar, num diagrama de papel com o cenário de um horizonte, sua observação. Solicitávamos, como dissemos, o registo da posição e da fase da Lua no céu em um mesmo horário pré-definido. Assim, por meio do registro sistemático do fenômeno, o estudante teria, ao final, uma representação das posições e fases da Lua num ciclo lunar a partir da perspectiva do observador terrestre.

A tarefa de registro revelou-se árdua e, ao longo do processo, os estudantes relataram dificuldades que os impediram de elaborar um registro adequado, e.g., nuvens impediam a observação correta da fase e posição, prédios bloqueavam a maior parte das observações e problemas de agenda para cumprir os horários combinados. Para realizar a tarefa, alunos lançaram mão da lunação publicada em calendários de que dispunham em casa, na agenda ou mesmo em pesquisas na 
internet. Isso acabou gerando um tipo de registro que, embora aprimorasse o uso dos calendários para previsão das fases, relação desconhecida por muitos, não nos amparava no processo de representar a lunação e a posição relativa, considerando a observação geocêntrica do sistema Terra-Lua.

Assim, a maioria dos estudantes desenhou as várias aparências da Lua e organizou-as conforme um calendário mensal, às vezes em registro misto de desenhos e fotografias obtidas quando as situações eram favoráveis. De maneira geral, os registros não eram fruto de observações vivenciais, alguns estavam incompletos e não expressavam posições e fases simultaneamente, indicando artificialidade. Nos melhores registros, os alunos produziram não mais do que uma coleção de fases da Lua, como exemplificado na Figura 3, que representa cerca de $90 \%$ do total das representações feitas pelos alunos.

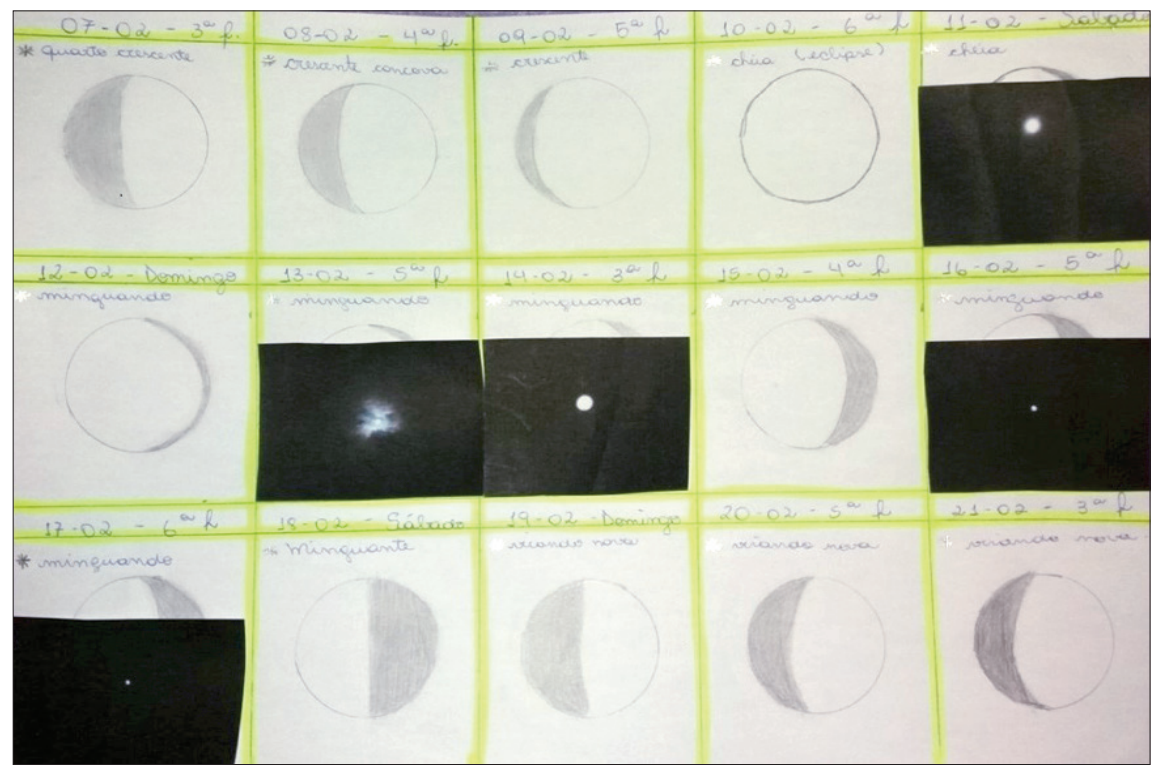

Figura 3. Fases da Lua registradas no papel, em forma de calendário semanal, com desenhos e fotografias.

Esse tipo de registro permite visualizar apenas a sucessão das fases e perceber uma historicidade cíclica. Os estudantes não faziam referência sobre as posições da Lua ou do Sol e sentiam-se inseguros quanto à qualidade do registro. Além disso, esse tipo de resultado frustrou nossas expectativas quanto a validade da observação a olho nu e seu registro como instrumento para construção do conceito de lunação.

As formas mais elaboradas desse tipo de registro, procuravam dar conta, além das fases, das posições sucessivas da Lua no céu, com algumas inconsistências como vemos na Figura 4. Esse tipo de registro, apoiado em representações de calendário, representa toda lunação no mesmo cenário de fundo, indicando a artificialidade da produção, além disso, nas variadas fases, a Lua ocupa sempre as mesmas cinco posições sem que apareçam as dificuldades do processo de observação. 


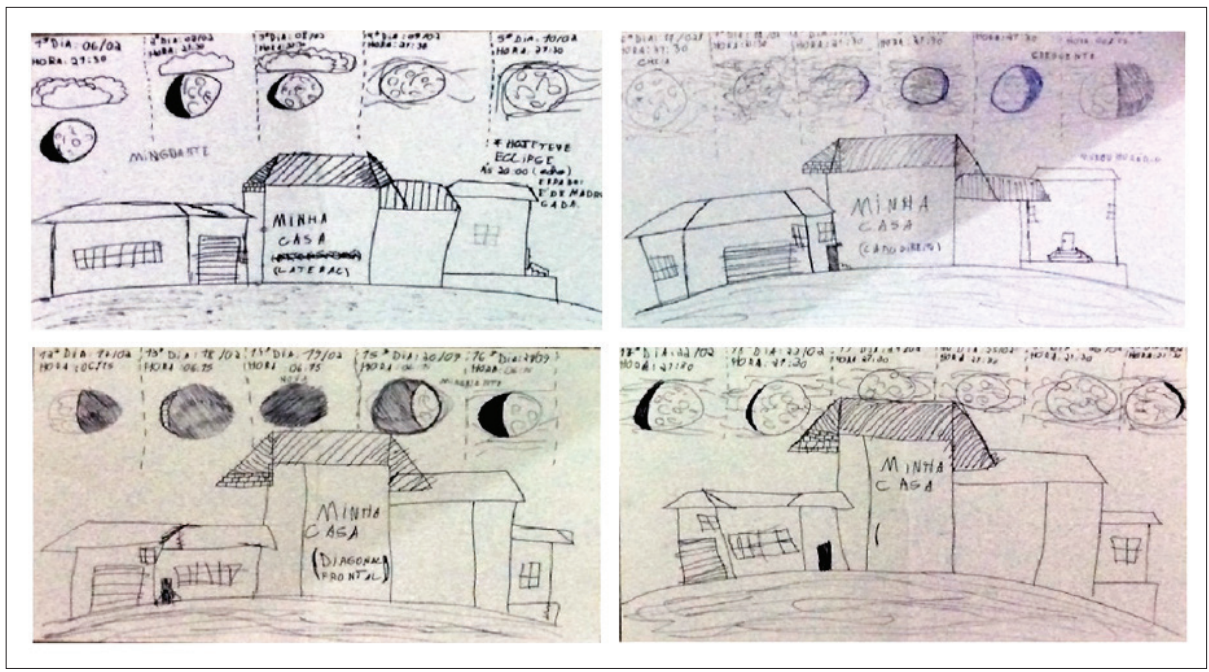

Figura 4. Fases e posiç̃̃es da Lua registradas no papel com desenhos e com referência ao horizonte.

O registro mais elaborado obtido nesse primeiro ano (Figura 5), foi feito por um estudante que se esforçou para representar o cenário observado a partir da varanda de seu apartamento. Registrou em desenhos e fotografias a fase e posição da Lua a cada dia, indicando as posições relativas e, nos momentos em que não conseguiu observá-la, seja devido as más condições atmosféricas ou por estar atrás dos edifícios, inferiu sua possível posição. No primeiro e segundo registros a Lua está em período crescente, no quinto registro a Lua encontra-se na fase Cheia, e segue para o período minguante no registro seguinte. Nota-se que o aluno não registra nada sobre as fases, quando não a observa diretamente, optando por registrar uma interrogação ou nuvens na possível posição inferida.

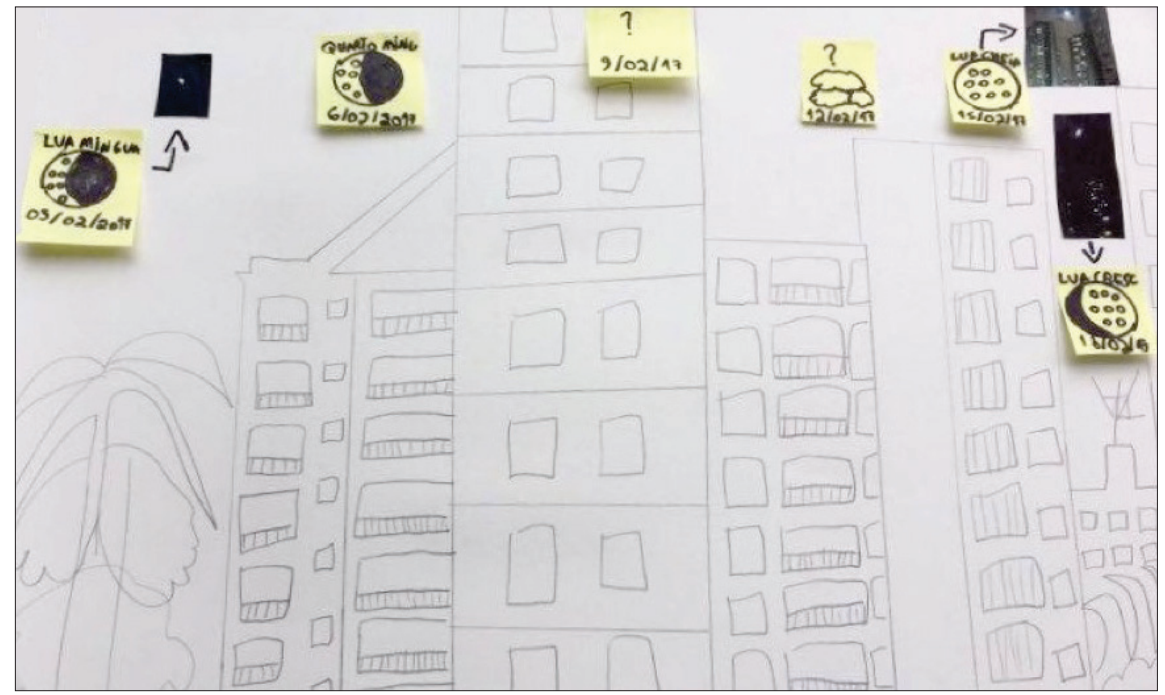

Figura 5. Representação das posições e fases da Lua registradas no mesmo cenário fixo tendo como referência 0 horizonte da residência do aluno. 
Ao final da atividade de observação, no primeiro ano, identificamos dois pontos importantes: o primeiro é o de que a maior parte dos registros teve lacunas e não promoveu uma apropriação adequada da lunação naquele momento. Acreditamos que além das dificuldades técnicas-operacionais já citadas, a pouca compreensão e domínio das variáveis em questão (horário, aparência, posição, horizonte, espacialidade) foram fatores determinantes para o relativo insucesso das observações. O segundo ponto se refere ao agenciamento dos alunos, que mobilizaram outros recursos procurando superar as dificuldades da observação de campo e dar conta das lacunas dos dados nessas observações. Essa mobilização, possibilitou a emergência de uma diversidade de novas interações e novos mediadores (e.g. fotografias e post-it), resultando em novas formas enunciativas, compreendidas pelo professor como contribuições a ser incluídas futuramente na estrutura da atividade. Assim, no ano seguinte utilizou esses instrumentos emergidos da agência dos alunos para alterar a estrutura e a dinâmica da atividade nos anos seguintes.

\subsection{INTERLÚDIO: REFLEXÃO E TRANSFORMAC̣̃̃O DA ATIVIDADE}

Antes de passarmos ao relato e análise do segundo ano da atividade de observação, cabe caracterizarmos a emergência de alguns processos que acabaram por marcar a necessidade de mudança na dinâmica desenvolvida ao longo do ano. Encerrada a atividade particular de observação, o professor continuou seu curso desenvolvendo as outras atividades previstas, que abordavam os conceitos de planeta, Sistema Solar, estrelas e constelações. Nelas, utilizou em sala de aula um simulador de observação astronômica de domínio público (Stellarium). O professor propôs uma série de atividades de observação da posição dos planetas e busca de algumas constelações.

O professor, introduzindo as formas de manuseio do programa, comentava sobre estrelas e planetas que seriam visíveis à noite. Motivados pelo uso da ferramenta em sala de aula, os alunos instalaram em aparelhos móveis versões similares de simuladores do céu, muitos dos quais o professor desconhecia. Os alunos foram estimulados a trazê-los para sala de aula e a fim de serem compartilhados com os colegas. Essas novas ferramentas chamaram a atenção do professor, que decidiu dedicar tempo de aula para aprender e discutir o seu uso com os alunos.

A interação entre professor e estudante que relatamos a seguir foi crucial para ampliar a consciência do professor sobre o uso dos programas como ferramenta didática, bem como para ampliar a consciência dos estudantes sobre representações do céu.

Durante uma aula, certa aluna trouxe instalado em seu celular o aplicativo Star Walk, com o qual é possível visualizar a posição das estrelas e planetas em tempo real. Enquanto mostrava o seu funcionamento para o professor (Figura 6a), aconteceu a seguinte interação que mostra a emergência de uma forma mais complexa de representação do céu.

Aluna: Viu, é onde o Sol está agora.

Professor: Nossa! E você vê o planeta Mercúrio ao lado, também!

Aluna: Pois é! É muito legalzinho esse aplicativo. 
Após esse momento, o professor pede que a aluna apontasse o aparelho para o chão, para localizar uma constelação diametralmente oposta ao Sol, porém, a estudante entende como um erro:

Aluna: Não, professor! Precisa apontar para o céu! Para cima!

Professor: Mas eu estou apontando! Só que para o céu que está abaixo de nós! Olha a Lua ali!

Aluna: Como?!? Nossa é mesmo! O céu está ao nosso redor!

No diálogo registrado pelo professor identificamos o momento da tomada de consciência da estudante de que o horizonte não era uma limitação para localizar a Lua. Dessa forma, ela supera o que chamamos de cegueira de horizonte.

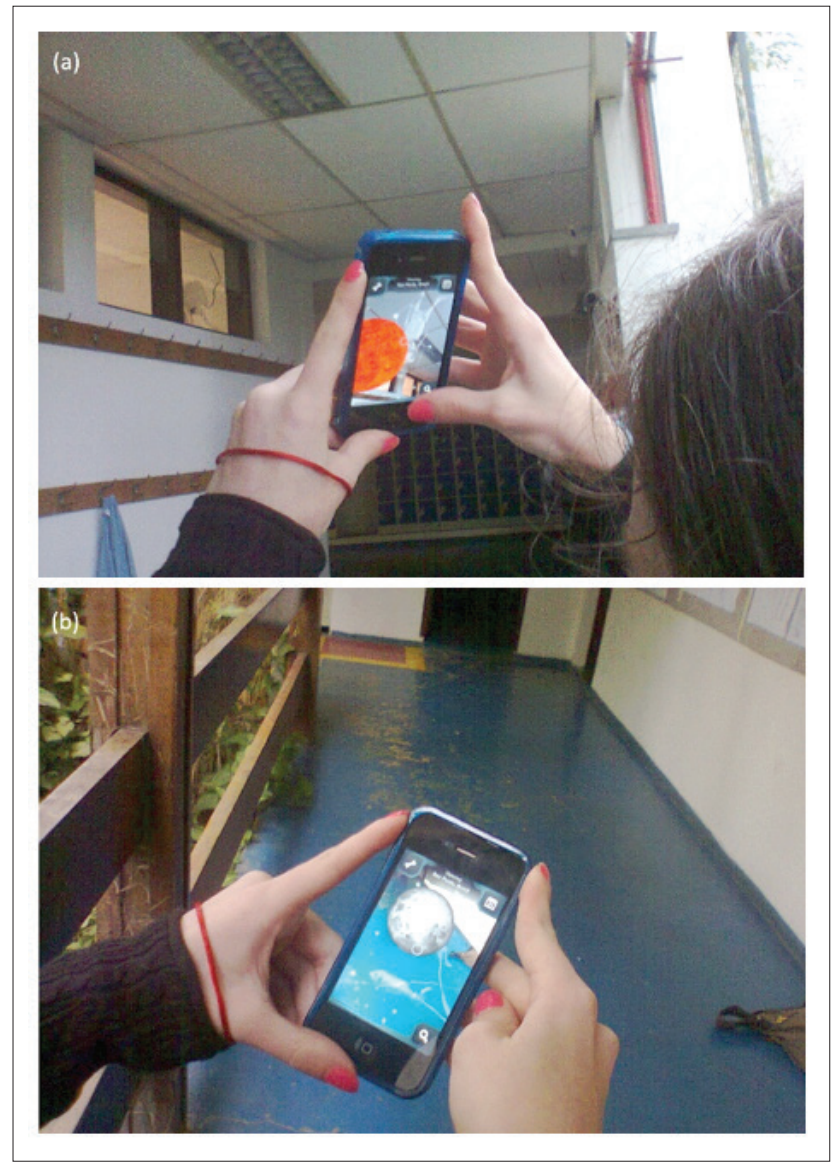

Figura 6. (a) Aluna observando a posição em tempo real do Sol de dentro da sala de aula, e (b) a mesma aluna apontado 0 celular para 0 chão e observando a posição da Lua abaixo do firmamento.

A aluna fascinada, começa então a apontar o celular para outras direções, tomando consciência de que podia observar o céu noturno do outro hemisfério por meio do aplicativo. É interessante observar que não são os novos instrumentos 
tecnológicos, de forma isolada, que permitem a tomada de consciência mais ampla e complexa do fenômeno estudado, mas as interações estabelecidas na atividade para este determinado artefato. Nela, estão mobilizados sistemas de conceitos construídos e complexificados ao longo das aulas, cuja cadeia de mediações possibilitou ao professor e à aluna que se apropriassem do celular e do aplicativo como mediadores para tornar mais complexo o conceito de céu. Desse momento em diante, para a aluna, céu não era mais o que estava 'em cima da gente', mas o que estava 'em volta da gente'. Evidenciamos uma ampliação da consciência da sua posição na Terra, não mais como um plano sob uma abóboda celeste, mas como uma esfera cercada por um céu.

Com o aplicativo foi possível superar aquela limitação conceitual a que nos referimos como cegueira do horizonte, pois seus recursos de visualização permitem desconsiderar os obstáculos físicos que estariam entre o observador e os astros observados, inclusive a linha do horizonte. Da mesma forma, o aplicativo permitiu superar a cegueira luminosa, que consiste em desconsiderar, na observação de astros, o ofuscamento da luminosidade solar na atmosfera.

Por outro lado, a mesma atividade permitiu que o professor tomasse consciência de novos instrumentos que poderiam substituir o instrumento 'papel' nas ações de registro da atividade de observação da Lua, superando o problema das lacunas no registro das posições da Lua, no ano seguinte.

\subsection{SEGUNDO ANO DE APLICAC̣ÃO DA ATIVIDADE: O REGISTRO DA OBSERVAÇÃO DA LUA POR MEIO DO APLICATIVO DE RECONHECIMENTO DO CÉU.}

No segundo ano, o professor compartilhou a nova ferramenta de observação com os alunos logo no início das aulas. Desse modo, os alunos se acostumaram rapidamente ao seu uso. Característico de uma geração que tem o celular como um dos principais instrumentos mediadores sociais, os alunos logo descobriram versões dos aplicativos com diferentes características e funções de modo que ampliaram substancialmente o repertório de instrumentos. Entretanto, o professor optou por não discutir previamente com os alunos a possibilidade de uso dos aplicativos para a observação e registro das fases da Lua.

Quando iniciaram a atividade de observação da Lua, os alunos já tinham seus aplicativos instalados e configurados. O processo de observação transcorreu sem muitos inconvenientes, os problemas que surgiram foram mais relacionados às configurações inadequadas e limitações de armazenamento dos aparelhos, dificuldade de operação com alguns aplicativos, configuração inadequada dos aplicativos (normalmente configurados com o céu do hemisfério norte), entre outros. O registro típico feito pelos alunos está exemplificado na sequência de imagens da Figura 7. 


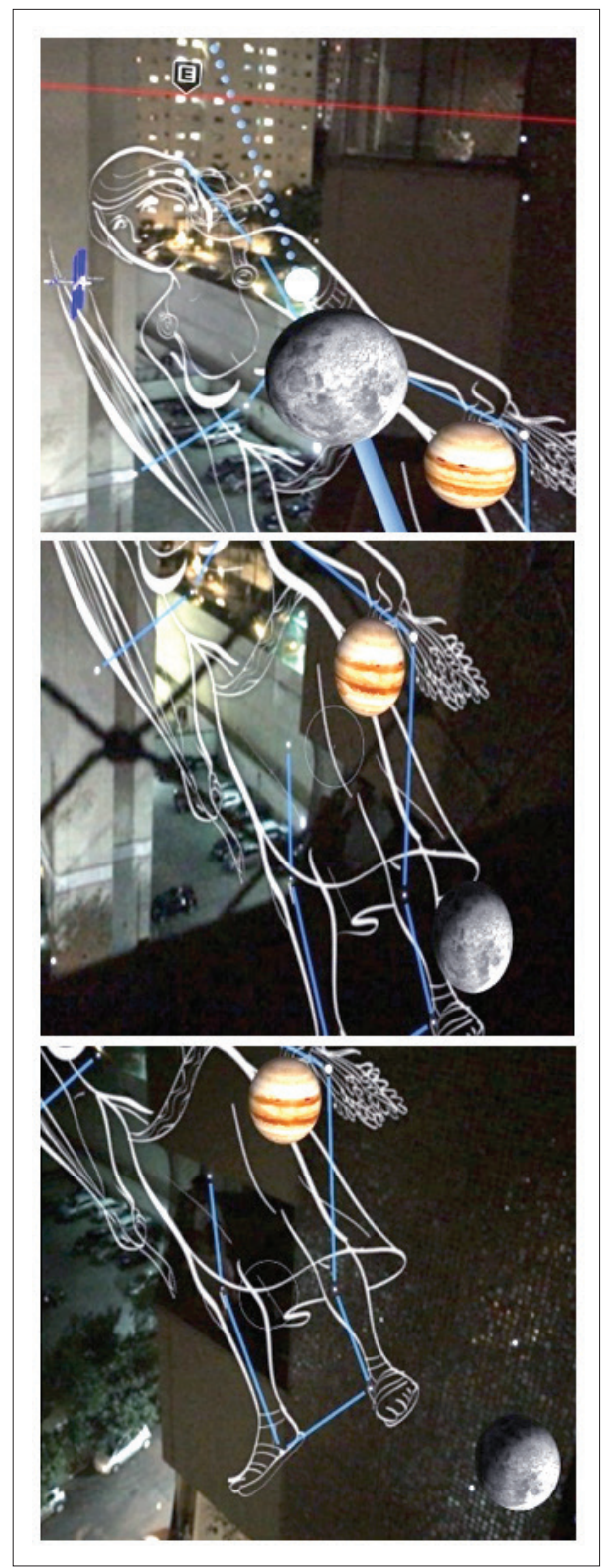

Figura 7. Posições da Lua observadas em três dias diferentes pela janela do quarto de um aluno. É possível notar o movimento do astro em relação à constelação de Virgem.

Nessas imagens, capturas de tela do celular de um aluno, é possível identificarmos a Lua, o céu e os prédios ao fundo vistos através da janela de seu quarto de dormir. Aparecem também, parte da constelação de virgem e o planeta Júpiter. Olhadas em conjunto e sequencialmente, podemos identificar a mudança da fase (de quase Cheia para Quarto-Minguante) e o mudança da posição relativa da 
Lua, considerando como referência os prédios ou a constelação de fundo. Assim, a posição da Lua, a cada dia, vai se deslocando para o canto inferior direito da imagem, afastando-se de Júpiter e da constelação que permanecem, praticamente, nas mesmas posições em todas as imagens.

Entretanto, quando as fotografias são dispostas separadamente em slides de uma apresentação, vistas individualmente no celular ou nos arquivos da plataforma de ensino a distância da escola, não permitia perceber o movimento lunar com facilidade. Por outro lado, os alunos que as dispuseram, lado a lado, sequencialmente, enunciavam movimento da lunação com muito mais propriedade do que os alunos que observavam imagens isoladas. As imagens em sequência permitiam que os alunos enunciassem em sala de aula o movimento de lunação com expressões típicas tais como: 'Olha! A Lua passou por toda essa parte da janela [apontando o dedo para percurso dela na foto] e foi para o chão’. Por outro lado, apesar da riqueza dos registros, muitos dos que analisavam as imagens obtidas separadamente não as integraram numa narrativa que expressasse a lunação. Em outras palavras, a falta de um instrumento de apresentação dos registros fotográficos que mostrassem o conjunto dos registros simultaneamente, se colocou como um problema importante, pois perdia-se a expressão da sequência temporal entre as posições da Lua com relação a Terra e, a posterior, associação com suas fases, considerando posição relativa Sol-Terra-Lua. Todos conceitos fundamentais para sustentar o conceito científico de lunação.

Nesse ano, uma nova lacuna apareceu, não mais aquela dos obstáculos físicos impedindo o registro das posições específicas, dificuldade superada com os aplicativos, mas a lacuna da interpolação das posições como trajetória. Parte dos alunos não conseguiu identificar, apenas pelas imagens feitas com o celular, a relação da trajetória com as fases da Lua. Compreender essa dificuldade foi fundamental para que o professor tomasse a decisão de, mantendo o uso dos dispositivos digitais, retomar o registro em papel para recuperar a perspectiva de conjunto do conjunto dos dados. É essa nova forma de registro que analisaremos na próxima seção.

\subsection{TERCEIRO ANO DE APLICAC̣ÃO DA ATIVIDADE: O REGISTRO FIXO E PERMANENTE DA OBSERVAC ÃO DA LUA - O OUARTO E A SALA DE AULA COMO OBSERVATÓRIO}

Neste ano, para introduzir a atividade foram necessárias algumas negociações e etapas preliminares. Depois de compartilhar a ferramenta de observação com os alunos, o professor apresentou alguns registros dos anos anteriores discutindo seus pontos fortes e fracos. Discutiu os problemas apresentados pelos alunos no ano anterior e discutiram encaminhamentos para eles. Finalmente, propôs a estratégia do 'papel expandido', na qual deveriam fazer registros de cada observação realizada em casa, de preferência nos seus quartos de dormir. Ao final da atividade, os alunos deveriam apresentar imagens do seu quarto como uma espécie de registro dos registros.

Os registros da lunação deveriam ser realizados conjugando a observação a olho nu, a observação com o uso do celular e o registro em papéis colados na parede dos quartos. Isso permitiria que os estudantes produzissem registros, mesmo nos 
dias em que falhassem na observação direta, de maneira que garantissem a história do fenômeno. Assim, como qualquer outra atividade em movimento expansivo, na medida que suas contradições vão sendo superadas, novas contradições emergem. Ou seja, nesse momento da atividade, os problemas que afloraram durante a observação foram de outra natureza como, por exemplo, a negociação com os pais para utilização das paredes da casa para o registro dos dados e a perda de registros por conta das interferências no cotidiano da casa do estudante.

Foi surpreendente o engajamento dos estudantes, que pode ser identificado pela excitação com a diversidade de observações exploradas e pela produção de uma grande variedade de registros. A estas produções, estavam associadas novas formas enunciativas que revelaram a apropriação que os estudantes tiveram das relações entres os conceitos trabalhados para a compreensão da lunação. Por exemplo, a Figura 8 mostra o registro de um aluno que usou post-its com desenhos para marcar as posições e fases da Lua na parede ao lado da sua cama. Na fotografia é possível identificar que o estudante referenciou a linha do horizonte com um barbante e registrou a cada dia as posições da Lua com o auxílio do aplicativo do celular. Quando apresentou o registro da fotografia de seu quarto, o aluno indicou a trajetória da Lua no céu, percorrendo com o dedo sobre a foto uma curva que ligava todos os registros em post-it e enunciou como sua fase variava. Por fim, inferiu posições e fases futuras, que ainda não havia registrado. $\mathrm{O}$ quarto do aluno havia se tornado uma espécie de mapa celeste e a parede do quarto, uma espécie de observatório primitivo, um Stonehenge domiciliar.

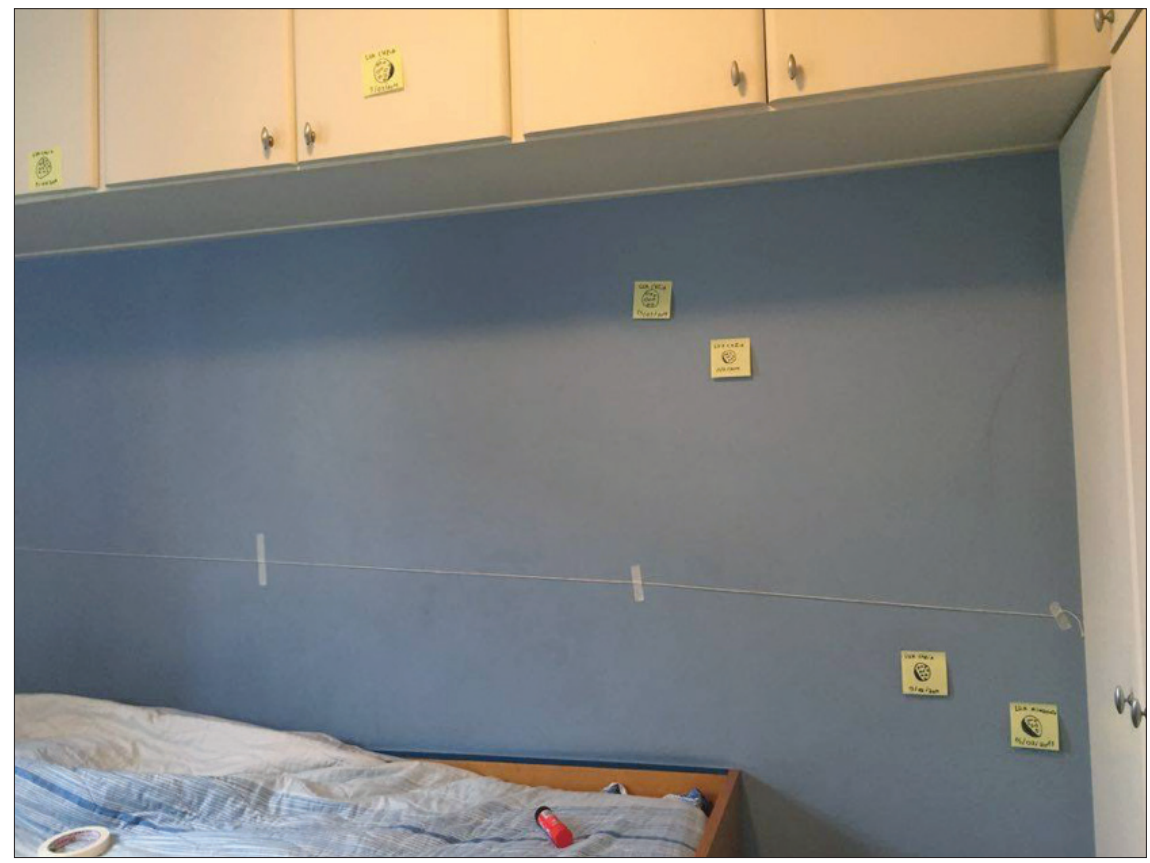

Figura 8. 0 quarto como observatório, cada post-it indica uma posição e a fase da Lua em seis dias diferentes e 0 barbante indica a linha do horizonte. 
O professor, estimulado pelo sucesso da atividade realizada na casa dos estudantes decidiu realizá-la, também, na sala de aula. Assim, nas aulas seguintes o professor e os estudantes começaram a realizar observações sistemáticas do movimento da Lua, registrando-o na parede da sala. Assim, em cada aula, durante as primeiras observações, o professor pedia a um estudante que realizasse a observação da Lua com o celular e fixasse o papel na parede, na direção observada, indicando a data e fase observada (Figura 9).

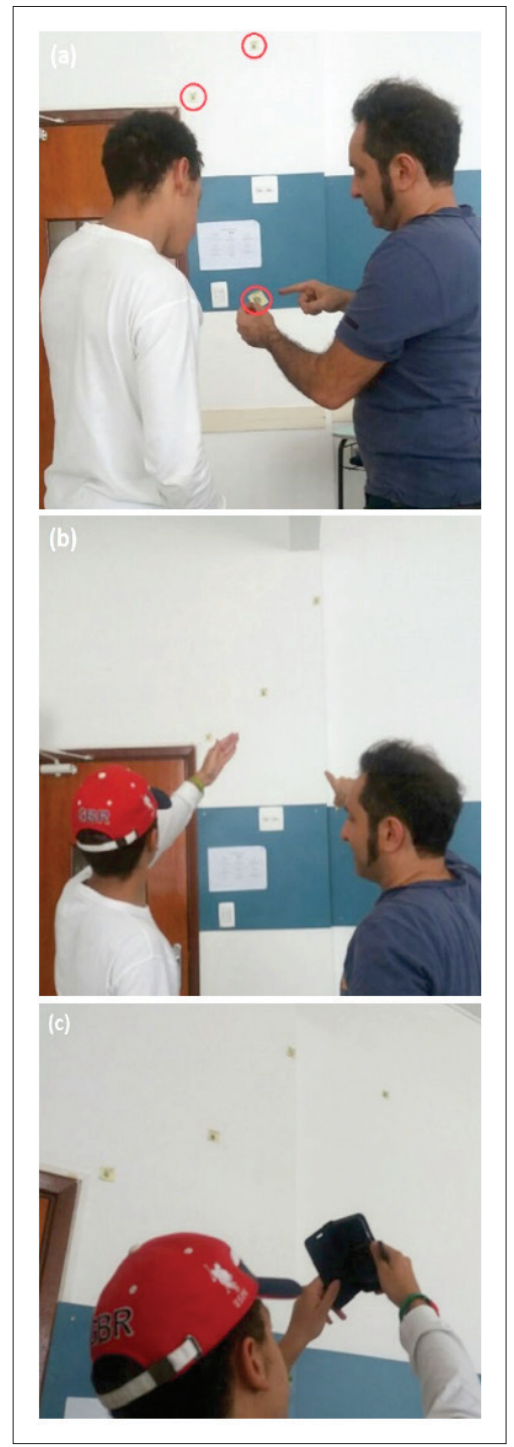

Figura 9. A sala de aula como observatório: (a) o professor pergunta ao estudante onde colocaria 0 post-it com a aparência da Lua; (b) 0 estudante explica 0 seu raciocínio e fixa o post-it, e, em seguida (c) confirma a posição da Lua com o celular. Os papéis com a data de observação e 0 desenho da aparência da Lua fixos na parede e na mão do professor estão destacados na figura (a). 
Depois de três registros iniciais, o professor passa a pedir que, antes da observação com o celular, o aluno analise os registros já efetuados e faça uma estimativa da próxima posição e fase esperadas (Figura 9a). Sem o celular, o aluno acompanha o histórico dos registros, descobre a orientação do movimento, gesticula indicando o caminho que a Lua percorreu e propõe uma estimativa para a posição futura da Lua (Figura 9b). Em seguida, pede que o estudante cole o papel na posição estimada e, então, utilize o celular para confirmar ou corrigir a posição escolhida (Figura 9c). É interessante ver o envolvimento e a alegria do aluno quando descobre que fixou quase exatamente na posição indicada pelo celular. Quando isso não ocorre, ele se autorregula, reposiciona o papel e explica as falhas de sua estimativa.

$\mathrm{O}$ auge dessa atividade se deu quando o aluno expressou o movimento da Lua no seu plano orbital terrestre, por meio de uma coreografia, na qual girava o corpo para acompanhar o plano orbital com os braços abertos, completando o giro inclinado, acompanhando os poucos registros das posições coladas na parede. Seu enunciado, por meio desse balé corporal, lhe conferiu uma espécie de fluência conceitual incorporada, ao inferir as posições futuras nos dias que transcorreram, demostrando um domínio sobre o fenômeno.

Nossa argumentação se baseia na evidência de que, ao apropriar novas ferramentas mediadoras, o estudante expressou a síntese da atividade, isto é, registrando todos os elementos necessários para expressar na perspectiva científica a lunação, seja por meio das suas manifestações orais, gestuais ou escritas. Em suma, o aluno apropriou-se do conceito-atividade de lunação e tomou o modelo para as fases da Lua em suas mãos.

\section{CONCLUSÃO}

Analisando a maneira como alunos eprofessor manipularam os instrumentos culturais e tecnológicos, construíram, desenvolveram e compartilharam os conceitos de Astronomia, entendemos que os dados mostram que a entrada de novas formas de mediação produziu o enriquecimento das concepções e percepções os alunos.

Esse artigo apresenta uma discussão em duas dimensões. A primeira, e mais central em nosso texto, trata-se do ensino e aprendizagem como desenvolvimento humano a partir da perspectiva sociocultural. Com base no referencial vygotskiano, construímos a proposição de que a aprendizagem conceitual pode ser considerada como uma complexificação conceitual e que está relacionada de maneira dialética com novas mediações na atividade, implicando na ampliação da consciência por meio da apropriação de ferramentas mediadoras.

Os dados apresentados e discutidos mostraram como os alunos elaboraram registros das fases da Lua cada vez mais precisos e ricos em mediações, com a apropriação e incorporação de novas ferramentas. Nessa perspectiva, esses registros mais complexos são manifestações de uma elaboração conceitual também mais complexas. Em outras palavras, a vivência da atividade de observação e registro das fases da Lua se traduziu em um autêntico aprendizado do modelo científico de lunação, que permitiu ao estudante explicar, prever e enunciar o fenômeno por meio de instrumentos mediadores que se tornam mais complexos com a evolução da atividade: o diagrama em papel, o aplicativo e o papel expandido. 
As interações discursivas em sala de aula, no último ano corroboraram claramente com esse resultado, mostrando que os estudantes, ao operar com os instrumentos mediadores, apropriaram suas funções como ferramentas psicológicas. Além disso, a tomada da Lua nas suas próprias mãos pode ser identificada em vários momentos da atividade, desde a emergência de novas ferramentas - dispositivos móveis e softwares de observação - até na emergência de novos enunciados verbais e gestuais dos estudantes, que enquadramos como autoria discente. Os alunos poderiam eles mesmo produzir seus próprios enunciados, suas vozes, dentro do discurso científico do modelo de fases da Lua.

A segunda dimensão em que podemos discutir o trabalho é sobre a formação de professor e o planejamento das aulas. Por exemplo, podemos nos perguntar: quem preparou as aulas? Desde o início do projeto tratou-se de uma parceria entre pesquisadores e professor, ou seja, a proposta da atividade adveio da revisão bibliográfica no contexto da pesquisa acadêmica e da experiência e autoria do professor. Além disso, a reflexão sobre a primeira aplicação da atividade não ter sido um sucesso ocorreu dentro de um espaço de diálogo entre ambos. Outro aspecto relevante, foi a inclusão do aplicativo como instrumento didático, a qual adveio da sensibilidade do professor, de uma pressão da escola pelo uso da tecnologia em sala de aula, e, mais importante, do espanto do aluno ao reconhecer que havia um céu estrelado sobre seus pés. Dentro desse cenário, novamente: quem elaborou a atividade? Ainda que não tenhamos delineado aqui uma proposta para formação de professor, reconhecemos o importante papel da atividade de pesquisa interventiva colaborativa (TEIXEIRA; MEGID NETO, 2017), por meio da qual o professor pode analisar e repensar sua prática, mas não numa reflexão individual - como um clandestino escondido com receio de ser descoberto - mas dentro de um ambiente de colaboração genuína, de um exercício do diálogo permanente com os outros professores, alunos e com sua própria prática.

Nesse sentido, o desenvolvimento do domínio e maestria pode ser encontrada na remodelação da atividade, em que o professor promove mudanças na atividade didática para propiciar aos alunos novas formas de interação e apropriação do objeto de estudo. Nesse sentido o professor tomou a atividade de ensino e aprendizagem nas mãos.

\section{REFERÊNCIAS}

BAXTER, J. Children's understanding of familiar astronomical events. International Journal of Science Education, v. 11, n. 5, p. 502-513, 1989.

BRASIL. Base Nacional Curricular Comum. Brasília: Ministério da Educação (MEC), 2017. Disponível em: <http://basenacionalcomum.mec.gov.br/>. Acesso em 08 mai. 2018.

CAMILLO, J.; MATTOS, C. Nova luz sobre velhos problemas: atividades experimentais numa perspectiva cultural-histórica. In: XII Encontro de Pesquisa em Ensino de Física. Águas de Lindóia: 2010. Disponível em: <http://www.sbf1.sbfisica.org.br/eventos/epef/xii/sys/resumos/ T0090-1.pdf>. Acesso em 08 mai. 2018.

CAMINO, N. Ideas previas y cambio conceptual en astronomía. Un estudio con maestros de primaria sobre el día y la noche, las estaciones y las fases de la luna. Enseñanza de las ciencias: revista de investigación y experiencias didácticas, v. 13, n. 1, p. 81-96, 1995. 
DANIELS, H. Vygotsky and pedagogy. London: RoutledgeFalmer, 2001.

DANIELS, H. Mediation: An expansion of the socio-cultural gaze. History of the Human Sciences, v. 28, n. 2, p. 34-50, 2015.

DAVYDOV, V. V.; ZINCHENKO, P. I. Vygotsky's contribution to the development of psychology. In: DANIELS, H. (ed.). Charting the Agenda: Educational Activity after Vygotsky. London: Routledge, p. 93-106. 1993.

ENGESTRÖM, Y. Non scolae sed vitae discimus: Toward overcoming the encapsulation of school learning. Learning and instruction, v. 1, n. 3, p. 243-259, 1991.

HASAN, R. The concept of semiotic mediation: perspectives from Bernstein's sociology. In: DANIELS, H. (ed.). Vygotsky and Sociology. London: Routledge, p. 80-91. 2012.

IACHEL, G.; LANGHI, R.; SCALVI, R. M. F. Concepções alternativas de alunos do ensino médio sobre o fenômeno de formação das fases da Lua. Revista Latino-Americana de Educação em Astronomia, n. 5, p. 25-37, 2008.

JAFELICE, L. C. (ed.). Astronomia, educação e cultura: abordagens transdisciplinares para os vários níveis de ensino. Natal: EDUFRN, 2010.

KALKAN, H.; KIROGLU, K. Science and nonscience students' ideas about basic astronomy concepts in preservice training for elementary school teachers. Astronomy Education Review, v. 6, n. 1, 2007.

KAVANAGH, C.; AGAN, L.; SNEIDER, C. Learning about phases of the moon and eclipses: A guide for teachers and curriculum developers. Astronomy Education Review, v. 4, n. 1, 2005.

KEELEY, P.; SNEIDER, C. I. Uncovering student ideas in astronomy: 45 formative assessment probes. Arlington, VA: National Science Teachers Association, 2012.

KIKAS, E. The impact of teaching on students' definitions and explanations of astronomical phenomena. Learning and Instruction, v. 8, n. 5, p. 439-454, 1998.

KOZULIN, A. Psychological tools: a sociocultural approach to education. Cambridge: Harvard University Press, 1998.

KOZULIN, A. Psychological Tools and Mediated Learning. In: KOZULIN, A. et al. (ed.). Vygotsky's Educational Theory in Cultural Context. Cambridge: Cambridge University Press, p. 15-38. 2003.

LAGO, L. G. Lua: fases e facetas de um conceito. 2013. Dissertação (Mestrado em Ensino de Ciências) - Programa de Pós-Graduação Interunidades em Ensino de Ciências, Universidade de São Paulo, São Paulo.

LELLIOTT, A.; ROLLNICK, M. Big Ideas: A review of astronomy education research 1974-2008. International Journal of Science Education, v. 32, n. 13, p. 1771-1799, 2010.

MATTOS, C. Conceptual Profile as a Model of a Complex World. In: MORTIMER, E. F.; ELHANI, C. N. (ed.). Conceptual Profiles: A Theory of Teaching and Learning Scientific Concepts. Contemporary Trends and Issues in Science Education. Dordrecht: Springer, 2014.

MATTOS, C. Livro didático na atividade educacional: a parte ou o todo? In: GARCIA, N. M. D.; AUTH, M. A.; TAKASHI, E. K. (ed.). Enfrentamentos do ensino de física na sociedade contemporânea. São Paulo: LF Editorial, p. 103-120. 2016. 
MERCER, N. Words and minds: how we use language to think together. London: Routledge, 2000.

MILLER, R. Vygotsky in Perspective. Cambridge: Cambridge University Press, 2011.

MULHOLLAND, J.; GINNS, I. College MOON Project Australia: Preservice Teachers Learning about the Moon's Phases. Research in Science Education, v. 38, n. 3, p. 385-399, 2008.

NATIONAL ACADEMY OF SCIENCES (NAS). Astronomy and Astrophysics in the New Millennium. Washington, D.C.: The National Academies Press, 2001.

NGSS. Next Generation Science Standards: For States, By States. Washington, D.C.: National Academies Press, 2013.

ORTEGA, J. L. A. Lacuna e enunciação no ensino de Física: quando a Física é mágica. 2012. Dissertação (Mestrado em Ensino de Ciências) - Programa de Pós-Graduação Interunidades em Ensino de Ciências, Universidade de São Paulo, São Paulo.

PASACHOFF, J.; PERCY, J. (EDS.). Teaching and Learning Astronomy: Effective strategies for educators worldwide. Cambridge: Cambridge University Press, 2005.

PLUMMER, J. D. Challenges in defining and validating an astronomy learning progression. In: ALONZO, A. C.; GOTWALS, A. W. (Eds.). Learning progressions in science: current challenges and future directions. Rotterdam: Sense Publishers, p. 77-100. 2012.

PLUMMER, J. D.; ZAHM, V. M. Covering the Standards: Astronomy Teachers' Preparation and Beliefs. Astronomy Education Review, v. 9, n. 1, 2010.

SAÇKES, M. Young children's ideas about earth and space science concepts. In: TRUNDLE, K.; SAÇKES, M. (Eds.). Research in Early Childhood Science Education. Dordrecht: Springer, p. 35-66. 2015.

SNEIDER, C.; BAR, V.; KAVANAGH, C. Learning about Seasons: A Guide for Teachers and Curriculum Developers. Astronomy Education Review, v. 10, n. 1, p. 10103-10103-22, 2011.

SODRÉ, F. C. R. Uma Proposta de Levantamento de Perfil Conceitual Complexo de Tempo. 2017. Tese (Doutorado em Ensino de Ciências) - Programa de Pós-Graduação Interunidades em Ensino de Ciências, Universidade de São Paulo, São Paulo.

SOLER, D. R.; LEITE, C. Importância e Justificativas para o Ensino de Astronomia: um olhar para as pesquisas da área. In: II Simpósio Nacional de Educação em Astronomia. São Paulo: 2012. Disponível em: <https://www.sab-astro.org.br/eventos/snea/ii-snea/atas/comunicacoes-orais/ co21/>. Acesso em 08 mai. 2018.

TEIXEIRA, P. M. M.; MEGID NETO, J. Uma proposta de tipologia para pesquisas de natureza interventiva. Ciência \& Educação (Bauru), v. 23, n. 4, p. 1055-1076, 2017.

TREVISAN, R. H.; PUZZO, D. Fases da Lua e eclipses: concepções alternativas presentes em professores de ciências de $5^{a}$ série do ensino fundamental. In: X Encontro de Pesquisa Em Ensino de Física, Londrina: 2006. Disponível em: < http://www.sbf1.sbfisica.org.br/eventos/epef/x/sys/ resumos/T0179-1.pdf>. Acesso em 08 mai. 2018.

TRUNDLE, K. et al. The Effect of Guided Inquiry-Based Instruction on Middle School Students' Understanding of Lunar Concepts. Research in Science Education, v. 40, n. 3, p. 451-478, 2010.

VERESOV, N. Introducing cultural historical theory: main concepts and principles of genetic research methodology. Cultural-historical psychology, v. 4, p. 83-90, 2010. 
VYGOTSKY, L. The Collected Works of L. S. Vygotsky. Volume 4: The history of the development of higher mental functions. Tradução Marie J. Hall. New York: Plenum Press, 1997.

VYGOTSKY, L. The Collected Works of L. S. Vygotsky. Volume 5: Child psychology. Tradução Marie J. Hall. New York: Plenum Press, 1998.

VYGOTSKY, L. The Collected Works of L. S. Vygotsky. Volume 6: Scientific legacy. Tradução Marie J. Hall. New York: Plenum Press, 1999.

VYGOTSKY, L. A construção do pensamento e da linguagem. São Paulo: WMF Martins Fontes, 2009.

WELLS, G. Semiotic mediation, viewed over time. In: DANIELS, H. (ed.). Vygotsky and Sociology. London: Routledge, p. 135-154. 2012.

WERTSCH, J. V. Voices of the mind: a sociocultural approach to mediated action. Cambridge, Mass: Harvard University Press, 1991.

\section{NOTAS}

${ }^{1}$ although students are able to describe the Moon phases, most of them are unable to explain why the phases occur, or give a coherent account of the Earth-Sun-Moon system (LELLIOTT; ROLLNICK, 2010, p.1786).

${ }^{2}$ voluntary attention, to logical memory, to the formation of concepts, and the development of will (VYGOTSKY, 1997, p.106).

${ }^{3}$ What was an external operation with sign, a certain cultural method of controlling oneself from outside, is converted into a new intrapsychological layer and gives rise to a new psychological system (VYGOTSKY, 1999, p. 55).

${ }^{4}$ a thorough and penetrating reflection of an object of reality in all it is complexity and diversity, in connections and relations to all the rest of reality (VYGOTSKY, 1998, p. 54).

${ }^{5}$ A atividade proposta inicialmente por Kavanagh et al. (2005) tem sido adaptada e realizada em diferentes situações (e.g. KEELEY; SNEIDER, 2012; PLUMMER, 2012; SAÇKES, 2015; SNEIDER; BAR; KAVANAGH, 2011).

\section{Submetido em 16/01/2018}

Aprovado em 18/05/2018

\section{Contato:}

Cristiano Mattos

Instituto de Física

Universidade de São Paulo

Rua do Matão 1371, Cidade Universitária

CEP 05.508-090 - São Paulo, SP - Brasil 